\title{
OP44
}

\section{EEFFECTS OF LUMINANCE DISTRIBUTION AND VIEW ON EVALUATION OF DISCOMFORT GLARE FROM WINDOWS \\ Toshie Iwata et al.}

DOI 10.25039/x46.2019.OP44

from

CIE x046:2019

\section{Proceedings}

of the

29th CIE SESSION

Washington D.C., USA, June 14 - 22, 2019

(DOI 10.25039/x46.2019)

The paper has been presented at the 29th CIE Session, Washington D.C., USA, June 14-22, 2019. It has not been peer-reviewed by CIE.

(C) CIE 2019

All rights reserved. Unless otherwise specified, no part of this publication may be reproduced or utilized in any form or by any means, electronic or mechanical, including photocopying and microfilm, without permission in writing from CIE Central Bureau at the address below. Any mention of organizations or products does not imply endorsement by the CIE.

This paper is made available open access for individual use. However, in all other cases all rights are reserved unless explicit permission is sought from and given by the CIE.

CIE Central Bureau

Babenbergerstrasse 9

A-1010 Vienna

Austria

Tel.: +4317143187

e-mail: ciecb@cie.co.at

www.cie.co.at 


\title{
EFFECTS OF LUMINANCE DISTRIBUTION AND VIEW ON EVALUATION OF DISCOMFORT GLARE FROM WINDOWS
}

\author{
Iwata, T. ${ }^{1}$, Ishimura, M. ${ }^{2}$, Tamura, D. ${ }^{3}$, Zhai, Y. ${ }^{4}$, Ishino, R. ${ }^{5}$ \\ 1 Tokai University, Kanagawa, JAPAN \\ ${ }^{2}$ NTT Urban Development Building Service Co. Tokyo, JAPAN \\ ${ }^{3}$ Leopalace 21 Co., Tokyo, JAPAN, ${ }^{4}$ Lightwings Architectural Design Co.,Ltd, Shanghai, CHINA \\ ${ }^{5}$ Toyota Home, Chiba, JAPAN \\ t.iwata@tokai-u.jp
}

DOI $10.25039 / \times 46.2019 .0 P 44$

\begin{abstract}
Recent studies suggest that window glare is affected by more parameters than the four main variables. The view through a window is one of the parameters which includes both environmental and humanistic factors. Two series of subjective experiments were conducted using a scale-model with an artificial window. The first experiment showed that higher contrast within the window resulted in higher discomfort glare evaluation, when the average luminance of the window was the same. The window with moderate frequency of dark-light bands resulted in higher discomfort glare evaluation than the window with uniform luminance. The second experiment showed that the horizontal division windows with the view of the sky and a building resulted in significantly higher glare evaluation than the window with the view of the sky and trees. It was suggested that glare evaluation decreases by increments in the preferability of the view for the horizontal division windows.
\end{abstract}

Keywords: Discomfort Glare, Luminance Distribution, Window view

\section{Introduction}

Lighting control strategies using daylight are important for sustainable building designs. However, glare from windows sometimes causes discomfort for occupants. A great deal of research has been carried out to develop glare indices for daylighting (Hopkinson, 1972, Tokura et al, 1996, Wienold and Christoffersen, 2006). The main variables that affect the experience of discomfort glare have been established. They are the luminance of the glare source, the luminance of the background, the angular size of the glare source, and the relative position of the glare source in relation to an observer's focal point. Originally these variables were determined to evaluate glare from indoor electric lighting. However, recent studies suggest that they are insufficient to evaluate glare from windows (Pierson et al. 2018).

It cannot be denied that indices predicting subjective response to light environment sometimes ignore the psychological and physiological state of occupants. This is because conventional stimuli-response research has avoided dealing with the other parameters which cannot be measured or expressed in physical quantities. The draft of the CIE TC 3-56 "Assessment of Discomfort Glare from Daylight in Buildings" report pointed out that there are not only environmental parameters but also human-related parameters.

The view through a window is one of the parameters which includes both environmental and humanistic factors (Shin et al.2012, Tuaycharoen and Tregenza, 2007). The former can be expressed in physical quantities (luminance distribution and power spectral density of glare source), while the latter is more qualitative and includes the subjective meaning or aesthetic value. Our previous experiment using an artificial window with uniform luminance distribution and actual windows suggests that the view through the windows can relieve discomfort caused by glare (Iwata et al. 2017). The other experiment shows that the subjects that dislike the view feel more discomfort than the subjects that like the view (Iwata, 2018). This result included the possibility that the subjects that gave a positive evaluation for preferability of the view also gave a positive evaluation for glare. Thus, view affects the glare evaluation in myriad ways. The 
objective of this study is to analyse the effects of the view through a window on discomfort glare evaluation.

\section{Experiment with non-uniform luminance window (1st experiment)}

\subsection{Methods}

In the first experiment, the effect of non-uniformity of luminance distribution on glare evaluation was tested. The subjective experiments were carried out using a 1:3 scale-model of a room ( $3 \mathrm{~m}$ $\times 4 \mathrm{~m} \times 2.4 \mathrm{~m})$ with an artificial window $(1800 \mathrm{~mm} \times 1260(\mathrm{H}) \mathrm{mm}$ ) illuminated by LED light (Panasonic,NNL-4600EDZLR9). Figure 1 shows the experiment room and Figure 2 shows a subject and an experimenter conducting the experiment.

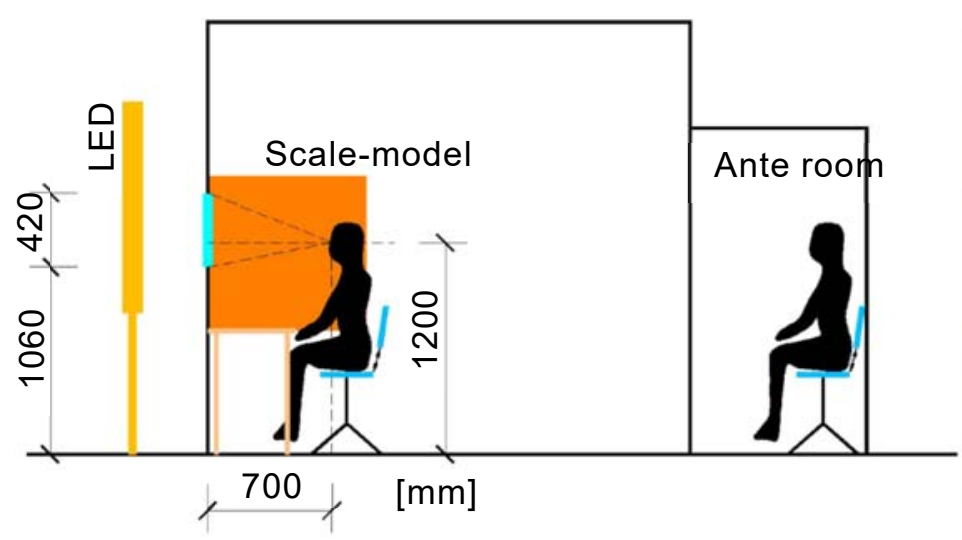

Figure 1 - Experiment room

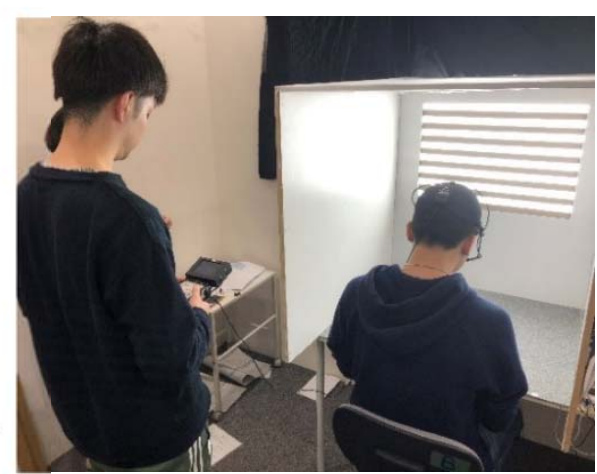

Figure 2- Subject and experimenter during experiment

The solid angle of the window from the subject's eyes was set to keep $0.44 \mathrm{sr}$ and the average luminance of the artificial window was set to $4000 \mathrm{~cd} / \mathrm{m}^{2}$. Table 1 shows the experiment conditions. The window was horizontally divided into light and dark bands. The frequency of light and dark bands was set at four states at two degrees of luminance ratio. In addition, the windows with uniform luminance and with vertical bands were evaluated. Eleven different windows were evaluated in total. Figure 3 shows luminance distribution of subject's visual field for four different conditions.

Table 1 - Experimental conditions ( $1^{\text {st }}$ experiment)

\begin{tabular}{|c|c|c|c|c|}
\hline Condition & $\begin{array}{l}\text { Luminance } \\
\text { of light part: } \\
\text { that of dark } \\
\text { part }\left[\mathrm{cd} / \mathrm{m}^{2}\right]\end{array}$ & \multicolumn{2}{|c|}{$\begin{array}{l}\text { Number of } \\
\text { light-dark } \\
\text { bands }\end{array}$} & $\begin{array}{c}\text { Frequency } \\
\text { of light and } \\
\text { dark bands } \\
\text { [cpd] }\end{array}$ \\
\hline UNI & 4000 & \multicolumn{2}{|l|}{0} & $\infty$ \\
\hline $\mathrm{H} 6 / 1$ & \multirow{4}{*}{$6000: 2000$} & \multirow{8}{*}{ Horizontal } & 1 & 0.03 \\
\hline $\mathrm{H} 6 / 2$ & & & 2 & 0.06 \\
\hline $\mathrm{H} 6 / 4$ & & & 4 & 0.12 \\
\hline $\mathrm{H} 6 / 8$ & & & 8 & 0.24 \\
\hline $\mathrm{H} 8 / 1$ & \multirow{4}{*}{$8000: 1$} & & 1 & 0.03 \\
\hline $\mathrm{H} 8 / 2$ & & & 2 & 0.06 \\
\hline $\mathrm{H} 8 / 4$ & & & 4 & 0.12 \\
\hline $\mathrm{H} 8 / 8$ & & & 8 & 0.24 \\
\hline V6/2 & $6000: 2000$ & \multirow{2}{*}{ Vertical } & 2 & 0.04 \\
\hline V8/2 & $8000: 1$ & & 2 & 0.04 \\
\hline
\end{tabular}




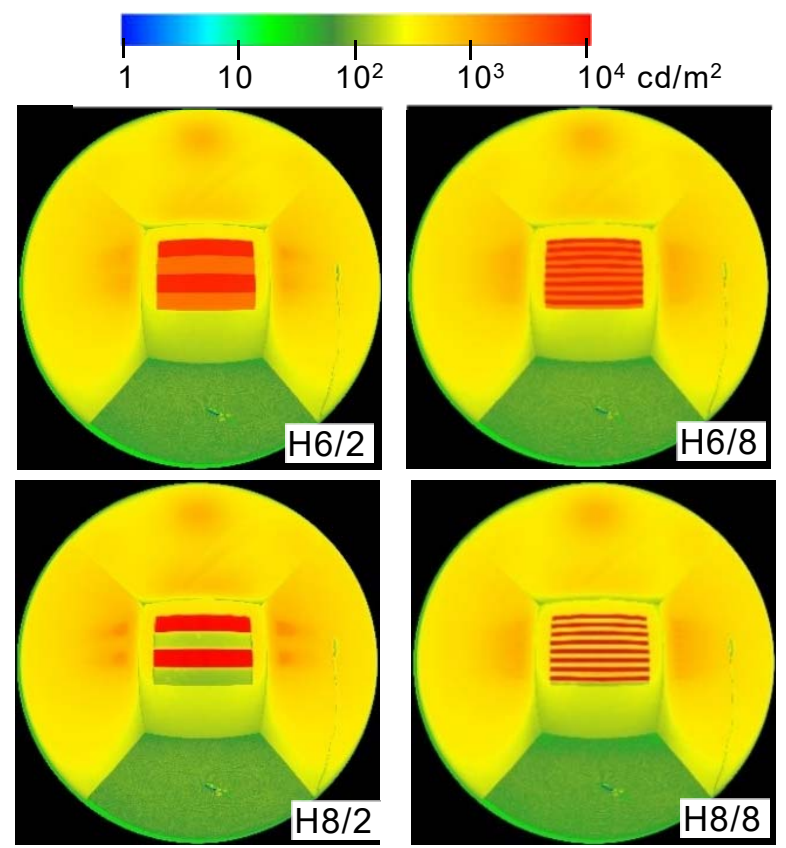

Figure 3- Examples of luminance distribution of subject's visual field

Twenty Japanese students (ranging between 20 and 23 years old) participated as subjects. The subjects entered the room and averted their gaze by looking at the floor of the scale model for a few minutes. Then the subjects looked at the window and assessed the glare using the Glare Sensation Vote (GSV) scale (0: just perceptible, 1: just acceptable, 2: just uncomfortable, 3: just intolerable). Each subject evaluated the eleven conditions. The eleven conditions were randomly ordered. The luminance distribution for each condition was measured by using an HDR camera system (Nikon D3300 and Sigma $4.5 \mathrm{~mm}, 1: 2.8$ EX DC circular fisheye). The glare indices, Daylight Glare Probability (DGP) (Wienold and Christdersen, 2005), Modified Daylight Glare Index (DGImod) (Fisekis and Davies, 2000), Predicted Glare Sensation Vote (PGSV) (Tokura et al., 1996) were calculated with Evalglare. The threshold luminance for detecting glare source was average task luminance (floor luminance) multiplied by five. The air temperature and relative humidity during the experiment were measured near the subject's position.

\subsection{Results}

During the experiment, air temperature in the test chamber was kept from 23 to $25{ }^{\circ} \mathrm{C}$ and relative humidity was kept from 35 to $40 \%$.

\subsubsection{Glare indices and Glare Sensation Vote (GSV) judged by subjects}

The normality test (Kolmozov-Smilnov test) showed that the GSV judged by the subjects for each condition had normal distribution. Therefore, the average value of GSV is used for analysis.

Although the average luminance of the window was kept at the same value, the glare indices, PGSV, DGP, and DGImod showed difference among the conditions. Table 2 shows glare indices as well as the average and standard deviation of GSV. Compared with the full-scale of each index, the differences in PGSV, DGP, and DGImod are small. 
Table 2 - Glare indices and Glare Sensation Vote for each condition

\begin{tabular}{|l|c|c|c|c|c|c|c|c|c|c|c|}
\hline & $\mathrm{UNI}$ & $\mathrm{H} 6 / 1$ & $\mathrm{H} 6 / 2$ & $\mathrm{H} 6 / 4$ & $\mathrm{H} 6 / 8$ & $\mathrm{H} 8 / 1$ & $\mathrm{H} 8 / 2$ & $\mathrm{H} 8 / 4$ & $\mathrm{H} 8 / 8$ & $\mathrm{~V} 6 / 2$ & $\mathrm{~V} 6 / 2$ \\
\hline $\begin{array}{l}\text { Source } \\
\text { Luminance[cd/m²] }\end{array}$ & 4137 & 3735 & 3839 & 3856 & 3816 & 7995 & 7961 & 7874 & 7182 & 4823 & 7444 \\
\hline Source solid angle[sr] & 0.43 & 0.42 & 0.40 & 0.38 & 0.39 & 0.21 & 0.21 & 0.21 & 0.20 & 0.32 & 0.22 \\
\hline PGSV & 1.31 & 1.32 & 1.30 & 1.34 & 1.32 & 1.37 & 1.39 & 1.38 & 1.31 & 1.24 & 1.38 \\
\hline DGP & 0.36 & 0.34 & 0.34 & 0.34 & 0.34 & 0.36 & 0.37 & 0.37 & 0.36 & 0.36 & 0.37 \\
\hline DGImod & 23.7 & 23.1 & 23.0 & 22.8 & 23.0 & 22.9 & 25.7 & 24.7 & 24.6 & 23.4 & 25.8 \\
\hline \hline GSV(ave) & 1.02 & 1.11 & 1.01 & 1.13 & 1.27 & 1.13 & 1.65 & 1.61 & 1.33 & 1.43 & 1.47 \\
\hline GSV(SD) & 0.89 & 0.71 & 0.62 & 0.71 & 0.96 & 0.91 & 0.56 & 0.70 & 1.09 & 0.86 & 0.71 \\
\hline
\end{tabular}

The correlation coefficients between indices and between each index and GSV judged by the subjects are shown in Table 3 . Shaded cells show the correlation coefficient calculated from all conditions and non-shaded cells show that calculated conditions with 8000:2000 of luminance ratio. The correlation coefficients between DGP and GSV and between DGImod and GSV are high.

\section{Table 3 - Correlation coefficient}

Conditions $\mathrm{H} 8 / 1$ to $\mathrm{H} 8 / 8$

\begin{tabular}{|c|c|c|c|c|}
\hline & PGSV & DGP & DGI & $\begin{array}{c}\text { GSV (by } \\
\text { subjects) }\end{array}$ \\
\hline PGSV & & 0.756 & 0.726 & 0.913 \\
\hline DGP & 0.419 & & 0.715 & 0.952 \\
\hline DGI mod & 0.547 & 0.824 & & 0.810 \\
\hline GSV (by subjects) & 0.395 & 0.800 & 0.779 & \\
\hline \multicolumn{5}{|c}{ All conditions }
\end{tabular}

\subsubsection{Effect of luminance ratio and frequency of light-dark band on GSV}

Figure 4 shows the relationship between frequency of light-dark band and GSV. When the luminance ratio was $8000: 1$, the window with $0.06 \mathrm{cpd}$ and the window with $0.12 \mathrm{cpd}$ resulted in significantly higher GSV than the window with uniform luminance and the window with 0.03 $\mathrm{cpd}$. The window with $0.24 \mathrm{cpd}$ showed no significant difference in GSV from the uniform luminance window and $0.03 \mathrm{cpd}$-window. When the luminance ratio was 6000:2000, no significant difference in GSV was found between different frequency of light-dark band.

When the light/dark frequency was $0.06 \mathrm{cpd}$ and $0.12 \mathrm{cpd}$, the window with $8000: 1$ of luminance ratio showed higher GSV than the window with 6000:2 of luminance ratio.

\subsubsection{Vertical division and horizontal division}

When comparing the horizontal division and the vertical division as shown in Figure 5, we can see the vertical division shows higher GSV for the window with the luminance ratio of 6000:2000. However, for the window with the luminance ratio of 8000:1, no significant difference in GSV was found between the horizontal division and the vertical division.

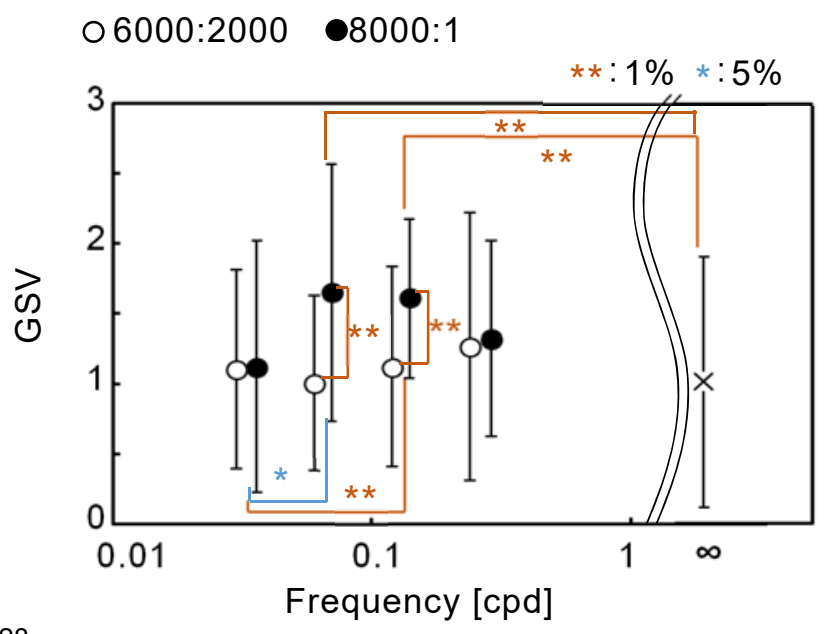

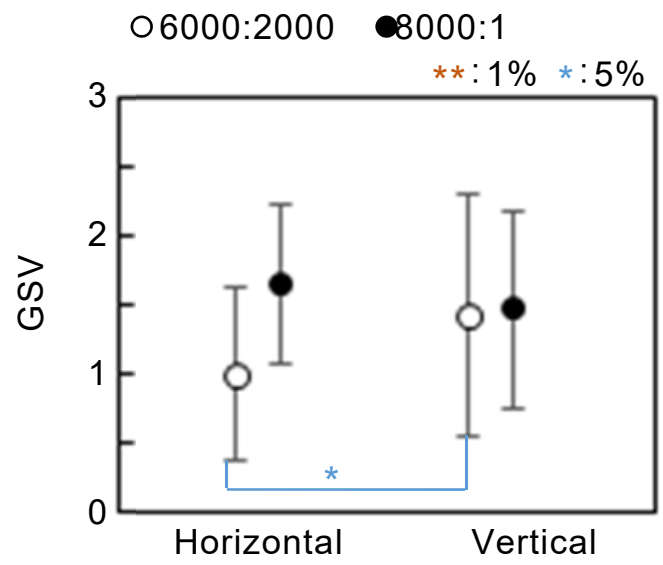

Dividing orientation: Orientation of light-dark band Figure 5 - Dividing orientation vs GSV 2019 


\section{Experiment with window displaying a view (2nd experiment)}

\subsection{Methods}

In the second experiment, the effect of subjective experience of what the observers see in the windows on glare evaluation was investigated. The test chamber and the scale model used in the first experiment (Figure 1) were used. The solid angle of the window from the subject's eyes was set to keep $0.44 \mathrm{sr}$ and the average luminance of the artificial window was set to 4000 $\mathrm{cd} / \mathrm{m}^{2}$.

Table 4 shows the experiment conditions. Windows with views (buildings, trees and the sky) as well as the window with light and dark bands (no view) were prepared. In total, eight different windows were evaluated.

Table 4 - Experimental conditions (2nd experiment)

\begin{tabular}{|c|c|c|c|c|}
\hline Condition & \begin{tabular}{|c|} 
Luminance of light \\
part: that of dark part \\
{$\left[\mathrm{cd} / \mathrm{m}^{2}\right]$}
\end{tabular} & \multicolumn{2}{|c|}{$\begin{array}{c}\text { Number of light-dark } \\
\text { bands }\end{array}$} & View \\
\hline $\mathrm{Vn}$ & \multirow{8}{*}{ 7000:1000 } & \multirow{3}{*}{ vertical } & 2 & No view (light part: $50 \%$ ) \\
\hline $\mathrm{VtC}$ & & & 2 & Trees:50\% (colour) \\
\hline $\mathrm{VtG}$ & & & 2 & Trees:50\% (grey) \\
\hline $\mathrm{Hn}$ & & \multirow{5}{*}{ Horizontal } & 1 & No view (light part: $50 \%$ ) \\
\hline $\mathrm{HtO}$ & & & 1 & Building: $50 \%$, trees: $0 \%$ \\
\hline $\mathrm{Ht} 17$ & & & 1 & Building: $33 \%$, trees: $17 \%$ \\
\hline $\mathrm{Ht} 33$ & & & 1 & Building: $17 \%$, trees: $33 \%$ \\
\hline $\mathrm{Ht} 50$ & & & 1 & Building:0\%, trees: $50 \%$ \\
\hline
\end{tabular}

To make the views, photos of the sky, a building and trees with different proportions were printed on transparent film and attached to the artificial window. Figure 6 shows images of the window view and Figure 7 shows luminance distributions of subject's visual field for different conditions. The ratio of the luminance was kept consistent at 7000:1000.

Twenty Japanese students (ranging between 20 and 23 years old) participated as subjects. There was no change in procedure between the two experiments. After the subject evaluated the glare using the Glare Sensation Vote (GSV) scale, the preferability of the view was evaluated on a 5-point scale (-2: unpreferable, -1: slightly unpreferable, 0: Neither preferable nor unpreferable, 1: slightly preferable, 2: preferable).

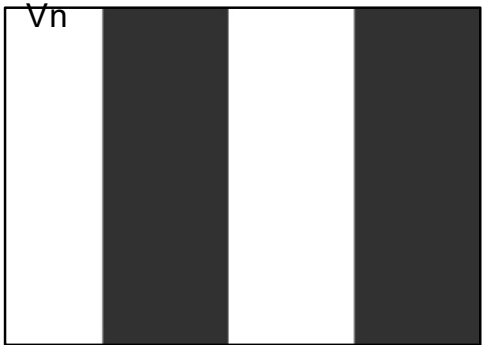

$\mathrm{Hn}$

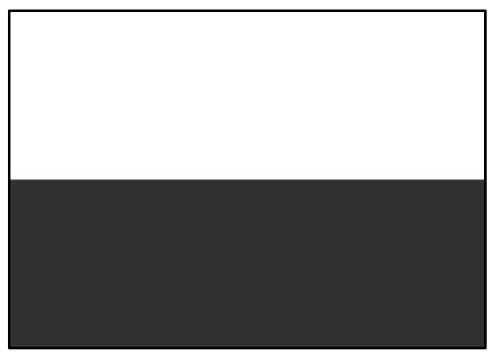

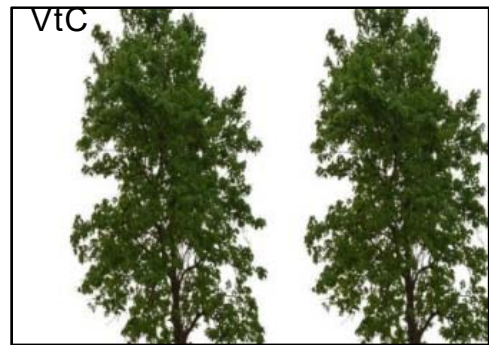

$\mathrm{Ht} 33$

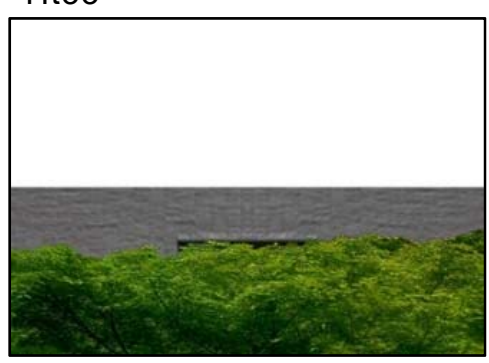

Figure 6 - Window views

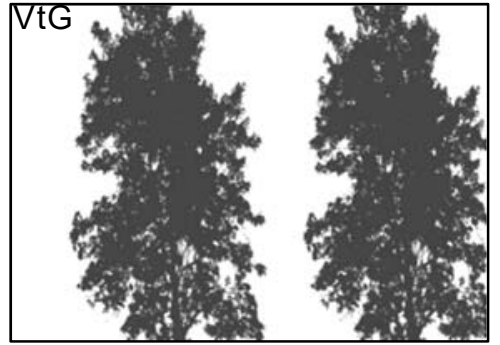

$\mathrm{Ht} 50$

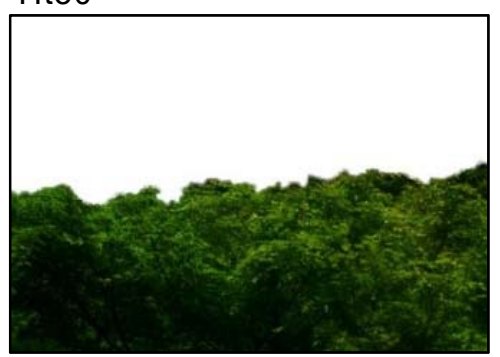




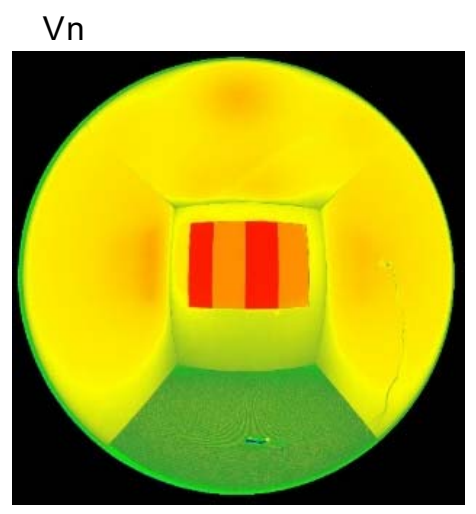

$\mathrm{Hn}$

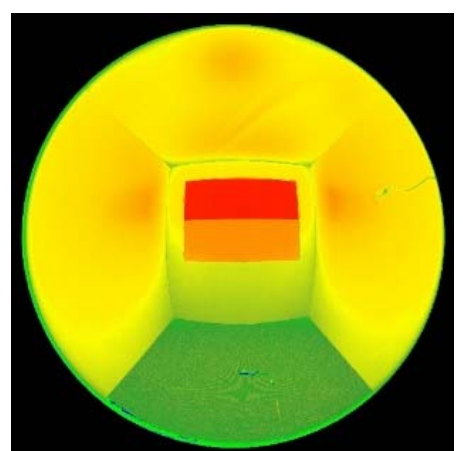

$\mathrm{VtC}$

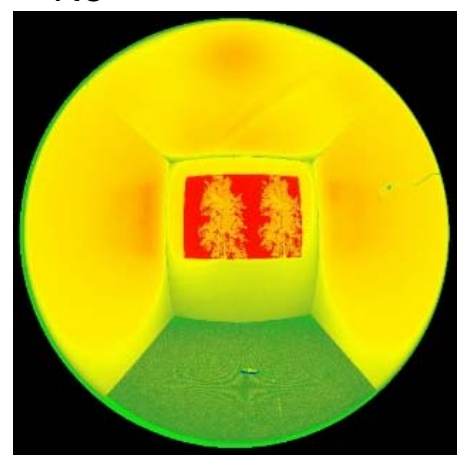

$\mathrm{Ht} 33$

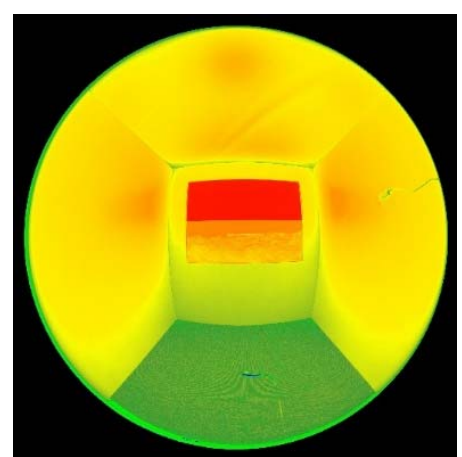

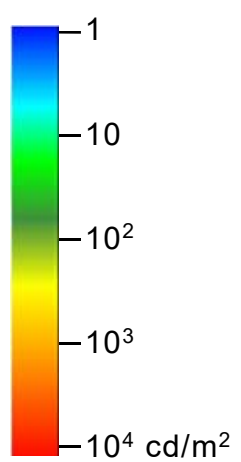

$\mathrm{Ht} 50$

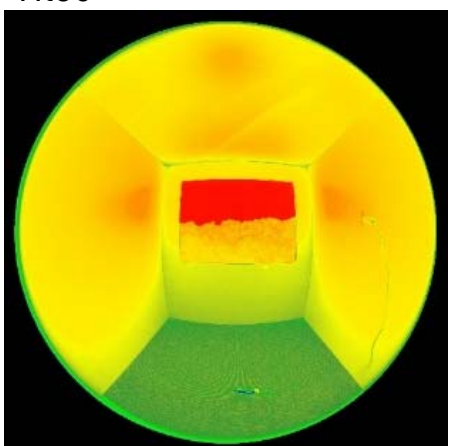

Figure 7 - Examples of luminance distribution of subject's visual field (2 ${ }^{\text {nd }}$ experiment)

\subsection{Results}

During the experiment, air temperature in the test chamber was kept from 23 to $24{ }^{\circ} \mathrm{C}$ and relative humidity was kept from 35 to $40 \%$.

The normality test (Kolmozov-Smilnov test) showed that the GSV judged by the subjects for each condition had normal distribution. Therefore, the average value of GSV is used for analysis.

Table 5 shows glare indices as well as the average and standard deviation of both GSV and Preferability. Compared with the full-scale of each index, the difference in PGSV, DGP, and DGI mod between conditions are small.

Table 5 - Glare indices and Glare Sensation Vote in $2^{\text {nd }}$ experiment

\begin{tabular}{|l|c|c|c|c|c|c|c|c|}
\hline & $\mathrm{Vn}$ & $\mathrm{VtC}$ & $\mathrm{VtG}$ & $\mathrm{Hn}$ & $\mathrm{Ht0}$ & $\mathrm{Ht} 17$ & $\mathrm{Ht} 33$ & $\mathrm{Ht50}$ \\
\hline Source Luminance[cd/m²] & 6770 & 7452 & 6771 & 6706 & 6868 & 6752 & 7506 & 6990 \\
\hline Source solid angle[sr] & 0.21 & 0.24 & 0.24 & 0.21 & 0.21 & 0.21 & 0.21 & 0.21 \\
\hline PGSV & 1.53 & 1.76 & 1.59 & 1.50 & 1.52 & 1.53 & 1.64 & 1.64 \\
\hline DGP & 0.37 & 0.38 & 0.38 & 0.34 & 0.35 & 0.35 & 0.36 & 0.35 \\
\hline DGImod & 25.4 & 24.2 & 24.7 & 22.1 & 22.1 & 22.2 & 22.5 & 23.0 \\
\hline \hline GSV(ave) & 0.82 & 1.20 & 1.26 & 1.22 & 1.41 & 0.93 & 1.42 & 0.88 \\
\hline GSV(SD) & 0.79 & 0.59 & 0.70 & 0.83 & 0.57 & 0.73 & 0.80 & 0.70 \\
\hline Preferability(ave) & -0.16 & 0.43 & 0.11 & -0.19 & -0.35 & 0.26 & 0.02 & 0.55 \\
\hline Preferability(SD) & 0.67 & 0.83 & 0.86 & 0.68 & 0.63 & 0.68 & 0.84 & 0.82 \\
\hline
\end{tabular}




\subsubsection{View and GSV}

Figure 8 shows GSV for each condition. When comparing no-view vertical division $(\mathrm{Vn})$ and horizontal division $(\mathrm{Hn})$, no significant difference in GSV was found between the vertical division and the horizontal division. In this experiment the ratio of luminance of the light part and that of the dark part was $7000: 1000$ which is between the two ratios used in the first experiment, in which only the window with a luminance ratio of 6000:2000 showed a difference between vertical division and horizontal division.

For the vertical division windows, those with views (coloured trees $\mathrm{VtC}$ or grey trees $(\mathrm{VtG})$ showed higher GSV than the no-view window $(\mathrm{Vn})$.

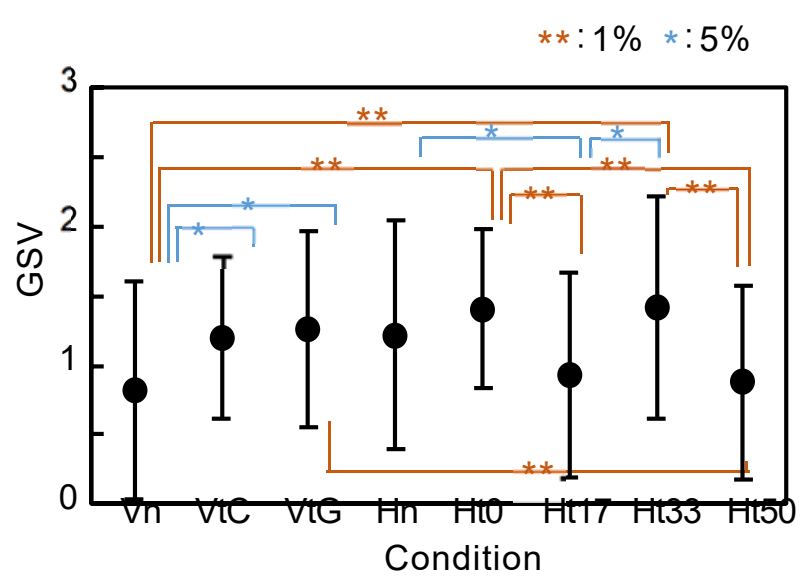

Figure 8 - GSV for each condition

For the horizontal division windows, those with the view of the sky and a building ( $\mathrm{Ht} 0)$ resulted in significantly higher GSV than the window with the view of the sky and trees ( $\mathrm{Ht} 50)$. The window with the view of the sky, trees and a building resulted in significantly higher GSV than the window with the view of only the sky and trees. Thus, it cannot be said that GSV decreases by increments in the percentage of tree area.

\subsubsection{Preferability of view and GSV}

Figure 9 shows the preferability of the view. For both the vertical and horizontal division, the preferability of the windows with trees $(\mathrm{VtC}$ and $\mathrm{Ht} 50)$ are significantly higher than the no-view windows ( $\mathrm{Vn}$ and $\mathrm{Hn})$. For the horizontal division, the preferability increased by increments in the percentage of tree area, except the cases with $17 \%$ of tree area $(\mathrm{Ht} 27)$ and $33 \%$ of tree area $(\mathrm{Ht} 33)$. Between them, no significant difference in the preferability was found.

Figure 10 shows the relationship between the preferability of the view and GSV. For the horizontal division windows, GSV decreases by increments in the preferability of the view.

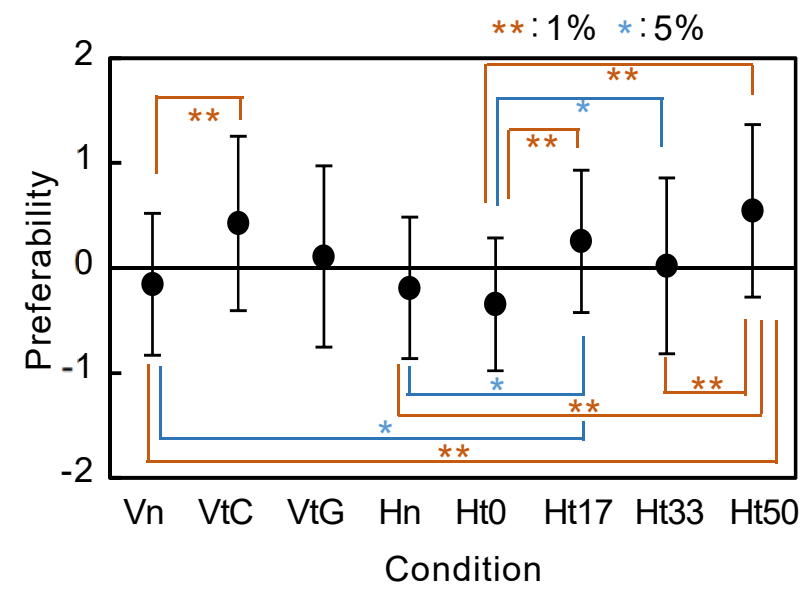

Figure 9 - Preferability for each condition

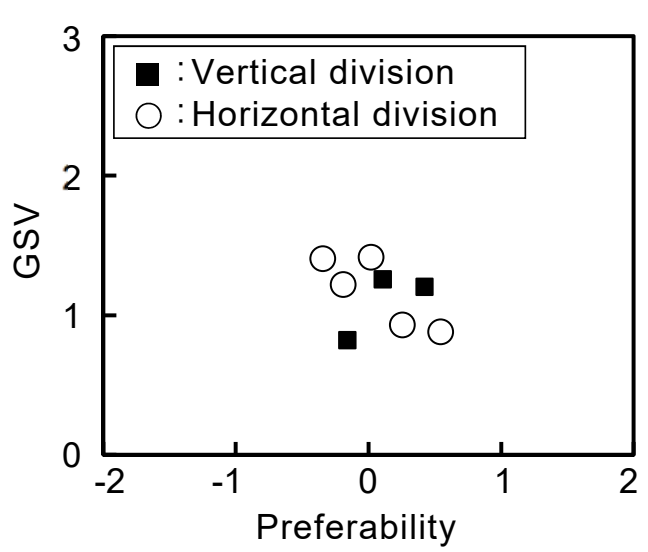

Figure 10 - Preferability for each

\section{Conclusions}

Two series of subjective experiments were conducted using a scale-model with an artificial window.

The first experiment showed that higher contrast within the window resulted in higher discomfort glare evaluation, when the average luminance of the window was the same. When the luminance ratio was $8000: 1$, the window with moderate frequency of dark-light bands resulted 
in higher discomfort glare evaluation than the window with uniform luminance. When the contrast is moderate (6000:2000), there is a significant difference in discomfort glare evaluation between vertical division and horizontal division.

The second experiment investigating the effect of view on discomfort glare showed that the vertically divided window with views (coloured trees or grey trees) showed higher GSV than the no-view window. For the horizontal division windows, those with the view of the sky and a building resulted in significantly higher GSV than the window with the view of the sky and trees. However, it cannot be said that GSV decreases by increments in the percentage of tree area. It could be inferred that GSV decreases by increments in the preferability of the view for the horizontal division windows.

\section{Acknowledgement}

This work is supported by JSPS KAKENHI Grant-in-Aid for Scientific Research (B) (No. 18H01599).

\section{References}

Fisekis K, and Davies M. 2003.Prediction of discomfort glare from windows. Light Res. Tech.; 35: 360-371.

Hopkinson, R.G., 1972, Glare from daylighting in buildings. Appl. Ergon.; 3, 206-215

Iwata, T.,2018. Difference in evaluation of discomfort glare from windows between Middleeastern and Japanese students EuroSun 2018 Conference Proceedings, International Solar Energy Society, DOI:10.18086/eurosun2018.06.14

Iwata, T., et al., 2017, Effects of task and views on discomfort glare from windows, Proc. of CIE mid-term conference, 105-112, DOI:10.25039/x44.2017.OP15

Pierson, C, Wienold, J., Bodart, M., 2018, Review of Factors Influencing Discomfort Glare Perception from Daylight. LEUKOS J. of the Illuminating Engineering Society of North America. DOI: 10.1080/15502724.2018.1428617

Shin JY, Yun GY, Kim JT. :View types and luminance effects on discomfort glare assessment from windows. Energy and Buildings (46)(2012)139-145.

DOI:10.1016/j.enbuild.2011.10.036.

Tokura M, Iwata T, Shukuya M. 1996. Experimental study on discomfort glare caused by windows, part 3: Development of a method for evaluating discomfort glare from a large light source. J. of Architecture, Planning and Environmental Engineering; 17-25.

Tuaycharoen, $\mathrm{N}$ and Tregenza, P.R., 2007. View and discomfort glare from windows, Lighting Res. Tech., 39, DOI:10.1177/1365782807077193

Wienold, J., Christoffersen, J.,2006, Evaluation methods and development of a new glare prediction model for daylight environments with the use of CCD cameras. Energy Build. 38, $743-757$ 